\title{
TWO CASES OF
}

\section{ABSENCE OF THE THYROID BODY,}

AND SYMMETRICAL SWELLINGS OF FAT TISSUE AT THE SIDES OF THE

NECK, CONNECTED WITH DEFECTIVE CEREBRAL DEVELOPMENT.

BY

THOMAS BLIZARD CURLING, FR.S.

SURGEON TO, AND LECTURER ON SURGERY AT, THE LONDON HOSPITAL.

Received May 13th.-Read June 25th, 1850.

The imperfect state of our knowledge of the office of the thyroid body, and the assistance often derived from facts, even of a negative character, in physiological investigations, independently of other circumstances of interest, lead me to consider the two following cases deserving of record.

Case I.-In July 1849, Dr. Little invited me to see a case of what he considered cretinism, at the Idiot Asylum at Highgate; and to examine some swellings at the sides of the neck, the nature of which were doubtful, but which had been suspected to be enlargements either of the lobes of the thyroid body, or of the lymphatic glands. The inmate was a female child, of stunted growth, ten years of age, and a native of Lancashire. She measured two feet six inches in height. Her body was thick, and her limbs disproportionately large and long. The dorsal surface of the body and limbs was hairy. The head was heavy looking, the forehead flat, and the fontanelles unclosed. The countenance had a marked and very unpleasant idiotic expression. The mouth was large, and the tongue thick and protuberant. At the outer sides of the neck, external to the sterno-cleido 
mastoid muscles, there were two tolerably symmetrical swellings, which had a soft doughy inelastic feel. Similar swellings, but smaller and less defined, were observed in front of the axilla. No enlargement existed in front of the neck, nor could the thyroid gland be perceived. The child had very little power of locomotion; but could manage to walk from chair to chair with a little assistance. She had no power of speech. She was able to recognise her parents, and evinced some manifestations of the exercise of the will. She seemed to direct the resident medical officer to be seated, and helped herself to mount on his knee.

I am indebted to Dr. Little for the following additional particulars. she had a severe attack of erysipelas whilst in the institution, after temporary recovery from which her mind seemed more developed. A considerable abscess formed in the thigh, which discharged copiously during many weeks. The wound healed; but erysipelas subsequently reappeared, accompanied with glossitis and stomatitis, from which she died exhausted six months after the commencement of her illness, and about fifteen months after admission into the asylum.

The body was examined twenty-four hours after death by Mr. Callaway, who has favoured me with the following particulars. The body was much emaciated. The swellings in the neck were much less in size than what they had been prior to her illness. They were composed of fat, and occupied the posterior triangle of either side of the neck, dipping downwards behind the clavicles, and filling the axillæ. They could be traced extending slightly over the infraspinal muscles, and the lowest angle of the scapula. They were not enveloped in capsule, but consisted of fat of a loose lobular structure, which seemed under the microscope to be made up of connecting tissue and fat globules. There was not the slightest trace of a thyroid body.

Case II.-In November 1849, a female infant, æt. six months, was sent to me by a surgeon for examination, on account of same anomalous swellings in the neck. The 
parents were healthy. The mother was 28 years of age, and this was her second child. The infant was plump, but had a marked idiotic expression,-a large face with a small head, and very receding forehead. The tongue was large and protruding from the mouth. On the sides of the neck, beyond the sterno-cleido mastoid muscles, were two soft symmetrical swellings, having a doughy feel, and incompressible. They were of an oval shape, lying obliquely across the sides of the neck, and extending from the edges of the trapezii to the middle of the clavicles. I was at once struck with the strong resemblance which this case presented, both in respect to the tumours and the general aspect, to the idiot at Highgate. The mother described the child to me as being helpless with its lower limbs : that is to say, as not being so strong as her former child. She afterwards became ill, refused to take nourishment, and died convulsed December 7th. On dissection of the body next day, nothing abnormal was observed in the brain, except a remarkably small development of the anterior lobes of the cerebrum. A very careful examination was made of the neck, but no thyroid nor trace of this gland could be discovered. The swellings in the neck were found to consist of superficial collections of fat tissue, without any investing envelope, and loosely connected to the surrounding parts.

I am not acquainted with any case on record in which a deficiency of the thyroid gland has been observed in the human body. But apart from the interest which must attach to the cases just related, from their great rarity, the development of adipose tissue forming symmetrical swellings in the neck, cannot fail to add to their importance; for it is highly probable, that this abnormal secretion of fat was dependent on the absence of those changes which result from the action of the thyroid, or on some imperfection in the assimilating processes, consequent on the want of this gland : and the facts here detailed may not be without significance in directing the researches of future inquirers into the use of this body. In countries where cretinism and bronchocele 
306 Mr. CURLING ON ABSENCE OF THE THYROID BODY.

prevail, it was long supposed, that there was some connection between the defective condition of the brain, and the hypertrophy of the thyroid. Pathologists have recently been inclined to view the coincidence of these two affections as accidental, or as having no direct relation. In the foregoing cases we have examples of a directly opposite condition, viz., a defective brain, or cretinism, combined with an entire absence of the thyroid, which may be regarded as tending to confirm the more modern opinion respecting the connection between cretinism and bronchocele. 